\title{
An innovative natural air-cooling system technique for temperature-rise suppression on the permanent magnet synchronous machines
}

\author{
Pedram Asef ${ }^{1} *$, Ramon B. Perpina ${ }^{2}$, and M. Reza Barzegaran $*^{3}$ \\ ${ }^{1}$ Electrical Engineering Department, Polytechnic University of Catalonia-BarcelonaTech, Barcelona 08019, Spain \\ ${ }^{2}$ Electrical Engineering Department, Polytechnic University of Catalonia-BarcelonaTech, Barcelona 08019, Spain \\ ${ }^{3}$ Phillip M. Drayer Dept. of Electrical Engineering, Lamar University, Beaumont, USA
}

\section{ARTICLE INFO}

\section{ABSTRACT}

\section{Article history:}

Received

Received in revised form

Accepted

Available online

\section{Keywords:}

Thermal transient analysis

Heat transfer

Permanent magnet synchronous machines

Finite element analysis

Computational fluid dynamic

\begin{abstract}
A segmented stator core due to closed-slot topology and type of used winding is subjected to a high temperature-rise. The application-oriented study is aimed to reduce temperature-rise of the conventional model at the stator core via radial and circumferential airflow ducts. This paper investigates a natural air-cooling system which decreases the temperature-rise in the stator core with no additional cost for very first time. The objective is reached without use of any external sources to pushes the air into the ducts. A three-dimensional finite-element (3D-FEA) thermal analysis based on an embedded cooling system with various number of ducts for a permanent magnet synchronous machines (PMSMs)

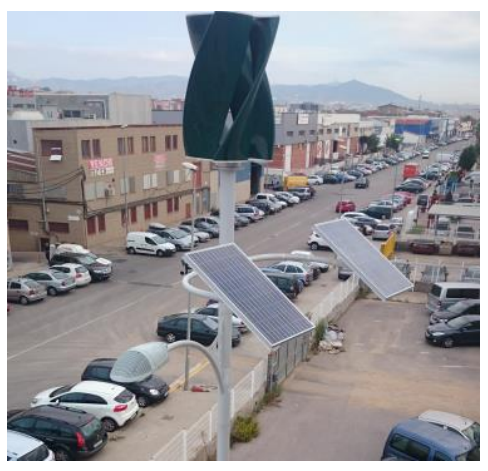
with two-layer fractional slot-concentrated stator winding is proposed, in which the coolant's path is a part of the research's innovation. A temperature distribution, and heat transfer comparison among all FE models such as conventional, two and four ducts in-core natural cooling systems will be comprehensively presented through freezing the electromagnetic performance. The alternative models using FEA, and computational fluid dynamic (CFD) are experimentally verified the innovative technique, in which the generator is operated by a vertical axis twisted savonius type wind turbine (VAWT).
\end{abstract}

2017 Elsevier Ltd. All rights reserved.

\section{Introduction}

\subsection{Motivation}

The PMSMs are subject to a high thermal stresses during their operation, if these stresses are observed, then that is possible to adapt the machine's control parameters such as current depending on the load and the supplying technique, in order to avoid overheating and a significant heat transfer problems. The conventional model observes with a considerable temperaturerise and related critical heat transfer at the stator core due to segmentation, in which closed-slot configuration is addressed for electromagnetic improvement. In fact, there are many type of cooling systems [1] to overcome this challenge. Although, they can be costly for a number of applications. We studied an innovative airflow coolant for an application-oriented case, in which the cooling system is exempt of employing any external resources to remove the heat in the stator core.

\subsection{Literature review}

The outer-rotor surface mounted PM synchronous machines (PMSMs), where two-layer fractional slot-concentrated stator winding is employed. The outer-rotor machines can reach a high torque at low speed, in which for the direct-drive small power generation applications with low-speed operation as [1].

\footnotetext{
* Corresponding authors.

e-mails: pedram.asef@upc.edu (Pedram Asef), mbarzegaran@lamar.edu (M. R. Barzegaran)
} 
R. Wrobel, et al. [2] studied a thermal analysis of a segmented stator winding design. While the thermal performance played one of the major factors limiting a machine's output capability, a thermal test on a complete prototype machine is an essential part of the design process. The method was allowed for a rapid and inexpensive assessment of the thermal performance of the complete machine and early identification of design modifications needed. The research has been applied to the design of a highly efficient and compact permanent-magnet traction motor. A thermal model for a single-tooth was developed and supported by tests to identify key heat transfer coefficients.

Reference [3], discussed the problem of temperature-rise that influencing the operation performance and also the life time of the PMSM. Based on double Fourier series decomposition, the research established a 3-D analytical model of PM eddy-current loss in the PMSM that considers the effect of time and space harmonics. By applying the thermal network model, the influence of different speed and load on temperature-rise has been analyzed, and a steady-state thermal analysis of the motor has been performed using finite element analysis. The paper caters the theoretical basis for the design of ventilation and cooling system of the PMSM.

M. Polikarpova, et al. [4] presented a direct liquid cooling system design for an 8 (MW) outer-rotor direct-drive permanent magnet synchronous motor (PMSG). The approach was novel for wind turbine generators, so its impact on the thermal behavior and reliability for the total electrical machine has been evaluated and reported. In addition, the article focused on a dramatic cost savings that can be realized with the development of a more effective stator windings cooling systems.

\begin{tabular}{|ll|}
\hline Nomenclature \\
$c$ & The specific heat $(\mathrm{J} / \mathrm{kg} \cdot \mathrm{K})$ \\
$\{v\}$ & The temperature $\left({ }^{\circ} \mathrm{C}\right)$ \\
$D_{s h}$ & Shaft diameter $(\mathrm{mm})$ \\
$D_{r}$ & Rotor diameter (mm) \\
$S_{d}$ & Effective slot-depth (mm) \\
$\alpha_{p}$ & Ratio of pole-arc to pole-pitch \\
$n_{m}$ & Minimum speed (rpm) \\
$P_{r}$ & Rated power (W) \\
$S_{w}$ & Slot-width (mm) \\
$\{L\}$ & The vector operator \\
$t$ & The time (s) \\
$Q$ & The heat source rate per unit volume $\left(\mathrm{W} / \mathrm{m}^{3}\right)$ \\
$\rho$ & The mass density (kg/m $\left.{ }^{3}\right)$ \\
$J_{c}$ & Current density (A/mm $\left.{ }^{2}\right)$ \\
$l_{s}$ & Active stack stator length \\
$m$ & Stator number of phases \\
$N$ & Number of turns per phase \\
$2 p$ & Number of poles \\
$Q_{s}$ & Total number of the stator slots \\
$\delta_{g}$ & Air-gap length (mm) \\
$\%_{\eta} \eta$ & Percentage of the efficiency \\
& \\
\hline
\end{tabular}

In reference [6], the authors discussed a thermal analysis and cooling system design of a dual mechanical port (DMP) using inner wound rotor is surrounded by the stator and the permanent magnet (PM) outer-rotor prototype machine are investigated. To predict the heat sources in actual operation, a transient cosimulation method has been presented. Thermal parameters and the flow distribution at the cooling ducts are calculated in detail. Finite-element analysis of the thermal field is carried out to obtain the temperature distribution and two typical thermal contacts are considered. A robust fully forced-air cooling system with inner rotor teeth ducts is proposed for the DMP machine and a 10-kW DMP machine is prototyped.

Marco Tosetti, et al. described a complete conjugate heat transfer analysis of a scaled-sized prototype of an integrated aircooled surface-mounted permanent-magnet generator for the "more-electric engine" application. Additionally, to predict and prevent the critical working conditions of the prototype, the adopted cooling system has been investigated using a complete fluid-thermal analysis. Due to the capabilities of computational fluid dynamic software, it has been possible to analyze the temperature and flow fields inside the machine, giving an idea about the distribution of the thermal quantities both inside the solid materials and above the surfaces [21].

The finite-element analysis (FEA), CFD, and lumpedparameter-based methodologies are employed for the entire study [7-12], [14-20], [24-28].

\subsection{Our contribution}

In this paper, a speed-functional model with radial and circumferential airflow ducts under 3-D thermal transient analysis of three FE models with two innovative structures are studied using an in-core circular natural air cooling system, regardless of any external sources (liquid and/ or air) at the stator yoke of an outer-rotor surface-mounted PM synchronous generator with closed-slot topology. Additionally, the proposed model is verified through its heat transfer calculation at each heat flux sensors, and along with experimental investigation. The CFD analysis is evaluated the heat transfer at a number of specific positions of heat flux sensors on the rotor and stator cores. Heat transfer coefficients are measured at 9 key positions in the stator and rotor cores, and accordingly a good performance of thermal analysis is also predicted. The natural airflow is assumed to vary over the range from 0 to $0.6\left(\mathrm{~m}^{3} / \mathrm{s}\right)$, and temperature between 18 to $35\left({ }^{\circ} \mathrm{C}\right)$. Moreover, the rotor speed limited to $500 \mathrm{rpm}$ due to malfunctioning in higher speeds of the data-loggers recording data from sensors on the machine. At last, the temperature-rise is suppressed by $11{ }^{\circ} \mathrm{C}$ without fail in the efficiency. Whereas, the electromagnetic performance of the FE models is also examined numerically and experimentally.

\section{Design and problem statement}

During the operation time, a high temperature-rise is experimentally measured in the stator core of the conventional FE model due to a high mechanical and thermal stresses. Under test bench, the temperature-rise of $83.8\left({ }^{\circ} \mathrm{C}\right)$, in which the direction of heat transfer is from inner surface of the stator (with a higher temperature) to outer surface of rotor (with lower temperature), that is governed by the second law of thermodynamics. Natural air cooling system based on the robustness of the FE results depends on the fitness of the generated mesh at the pre-calculation stage. Thermal FE modelling should be taken into account free of any following errors at this stage (1) improper geometric description (if an axial 
Table 1 Initial design of the machine geometry

\begin{tabular}{c|cc}
\hline Variable & \multicolumn{2}{|c}{ Linear current density fixed } \\
\hline$l_{s}$ & 100 & $\mathrm{~mm}$ \\
$D_{s h}$ & 50 & $\mathrm{~mm}$ \\
$D_{s e}$ & 410 & $\mathrm{~mm}$ \\
$\delta_{g}$ & 0.6 & $\mathrm{~mm}$ \\
$S_{w}$ & 15 & $\mathrm{~mm}$ \\
$S_{d}$ & 50 & $\mathrm{~mm}$ \\
$n_{m}$ & 150 & $\mathrm{rpm}$ \\
$P_{\mathrm{r}}$ & 6 & $\mathrm{~kW}$ \\
$Q_{s}$ & 36 & \\
$\alpha_{p}$ & 0.55 & \\
$2 \mathrm{P}$ & 40 & \\
$m$ & 3 & \\
\hline
\end{tabular}

symmetry and/ or rotational symmetry has been accounted without considering that an anti-symmetric load), (2) a poor definition of the used materials, for instance the limit of Poisson's ratio at isotropic materials, (3) improper definition of the load that is not recommended to simplify a complex load states or a number of loads with one load, (4) a wrong boundary expresses, (5) choosing a wrong kind of analysis (depends on the case), (6) singularity concept existing in the model which leads the points in the model where values tend toward an infinite value; FE model, where the infinite density and gravity are equivalent to an infinite stress in a sharp corner [22]. Therefore, a good mesh can be successfully generated for all three FE models.

The design solution alternatively resolves the problem using an innovative airflow path, in which the radial ducts are perpendicular to the shaft and pushes the air into the ducts due to rotation of the shaft and its path to out of housing, where we expect the natural airflow to vary over the range from 0 to 0.6 $\left(\mathrm{m}^{3} / \mathrm{s}\right)$. Fig. 2 illustrates the main air-flow path, in which the innovative models consist of circumferentially (circular at the stator yoke) and axially (from the circular path to the inner face of the ducts). In continue, the heated air-flow goes out through the gap between the stator core and the shaft. Moreover, position of heat flux sensors is shown, in which positions 1 , and 3 are on a pole-pair. Position 2, in the center of rotor yoke. Positions 4, and 5 on the stator centerlines of the coil front/ and bottom faces. Positions 6, 7, 8, and 9 at the different points of the stator core.

Fig. 3 shows that ducts are introduced to separate the machine axial segments for enhance the thermal dissipation capability with relevant $(\mathrm{r}=3.8 \mathrm{~mm})$ dimensions. Table. 2 represents the used materials for different parts of the models with their thermal specifications such as thermal conductivity and specific heat which greatly affect the accuracy of thermal analysis. The problem of the conventional model is determined after a careful steady-state thermal analysis using lumped-circuit (LC) and FE methods that Fig. 3 carries the results under condition of $35\left({ }^{\circ} \mathrm{C}\right)$ ambient temperature and $150(\mathrm{rpm})$ rated speed of the shaft. The LC method which modeled similar to an electrical circuit solves the steady-state temperatures at each node via solving a set of non-linear equations [23]

$$
\Delta T=P \times R
$$

where $\Delta T$ indicates the temperature-rise that corresponds to the voltage of electrical circuit, $P$ stands for power source that corresponds to current of electrical circuit, as well as $R$ shows thermal resistance that corresponds to electrical resistances of electrical circuit. The FEA based on a 3-D model solves partial differential equations (PDEs) using ANSYS multi-physics

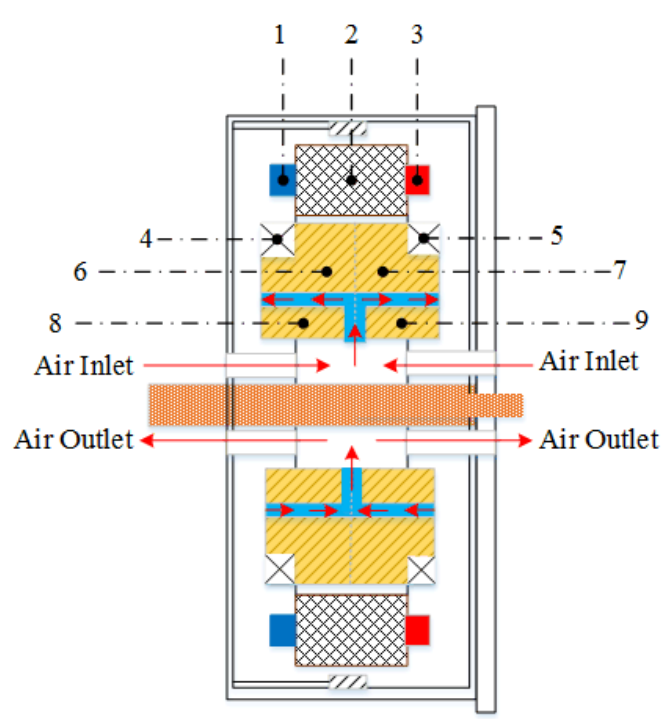

Fig. 2. The main heat transfer paths and position of heat flux sensors on the rotor and stator cores

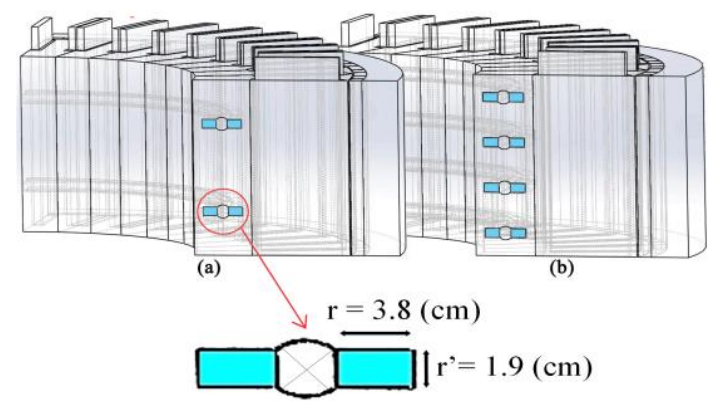

Fig. 3. 3-D sketch of the innovative coolant models with, a) 2ducts, and b) 4-ducts

engineering, where the heat transfer at the body of the model is controlled using below heat equation [24]

$$
Q=\rho C\left(\frac{\partial T}{\partial t}\right)-\nabla \cdot(k \nabla T)
$$

where $Q$ is the heat source, $\rho$ is the density, $C$ is the heat capacitance, and $k$ shows the thermal conductivity. Additionally, extra transverse heat flux terms of the convection and with regarding to Fig. 3, the stator core of the conventional model is the major challenge to cool up. However, the cost of this design process is highlighted, thus, the innovative FE models are accounted to adjust the temperature-rise of stator core cooling system.

Table 2 Materials and thermal specification

\begin{tabular}{c|lcc}
\hline Name & Materials & $\begin{array}{c}\text { Thermal } \\
\text { Conductivity } \\
\left(\mathrm{W} / \mathrm{m} /{ }^{\circ} \mathrm{C}\right)\end{array}$ & $\begin{array}{c}\text { Specific Heat } \\
\left(\mathrm{kJ} / \mathrm{kg} /{ }^{\circ} \mathrm{C}\right)\end{array}$ \\
\hline Stator core & M350-50A & 38 & 0.45 \\
Rotor core & M350-50A & 38 & 0.45 \\
Magnets & Nd-Fe-B & 10 & 0.45 \\
Winding & Copper & 401 & 0.38 \\
insulation & Kapton & 0.2 & 1.7 \\
Coil dividers & Nomex & 0.14 & 1.3 \\
\hline
\end{tabular}


This coolant technique can be complex and time consuming but considering thermal behavior of the PMSMs is very significant. Therefore, the increase of temperature may deteriorates the mechanical and electrical strength of the coil insulations and stator core, raises the stator coil resistance, and strongly decreases the lifetime of involved parts (stator core including windings) which tends to a terrible traffic accident. In order to determine the temperate distribution at the electrical machines, following states are considered, (1) accurate calculation of the losses, (2) properties of the cooling fluid and thermal characteristic of the magnetic (in this case, the properties of ambient temperature is measured at the sea level due to location of the generator), (3) proper definition of conductive and insulating parts (in this study, class A insulation per IEEE 177 and 101 standards is selected), (4) accurate analysis of heat conduction and Internal heat generation since the core-loss distribution is completely different in various positions of the stator core, 3-D transient thermal FEA should be used to analyze the temperature distribution for the most accurate simulation. The heat transferred by radiation is ignored. The partial differential equation of the heat conduction and convection is expressed [8] as

$$
\rho . c\left(\frac{\partial T}{\partial t}+\{V\}^{T} \cdot\{L\} T\right)=\{L\}^{T} \cdot(|D| \cdot\{L\} . T)+Q
$$

where $\rho$ is the mass density, $c$ is the specific heat, T $(\mathrm{K})$ shows mass transport of heat; $\{L\}$ is the vector operator, $|D|$ is the temperature, $t$ stands for time, $\{V\}$ is the velocity vector for conductivity matrix, and $Q$ is the heat source rate per unit volume. It should be mentioned that for steady-state thermal analysis, the first term on the left-hand side of Eq. 3 should be zero.

At this stage, the iron losses as function of temperature is calculated using Bertotti's iron loss separation models [29-30], in which skin effect has been accounted through following equation. The calculation results have been reported in Table 1.

$$
P_{f e}=k_{h}(f, B) f B^{h(B)}+k_{e}\left(\frac{\sinh (d \sqrt{f}-\sin (d \sqrt{f})}{\cosh (d \sqrt{f)-\cos (d \sqrt{f})}}\right) f^{1.5} B^{\beta}
$$

where $k h f, B, h(B)$ and $k e B$ are polynomials in $f$ and $B$.

Fig. 4, presents how the temperature distribution using steadystate analysis in the machine's parts using the lumped-circuit and FEA.

In the CFD modelling, 1.543 million volume cells are used, in which the typical cell edge size is $3(\mathrm{~mm})$, and the axial length of the model is $100(\mathrm{~mm})$. The symmetry, and $90^{\circ}$ periodic boundary conditions are applied. In addition, the commercial CFD code ANSYS is used for the related analysis.

Table 3. Losses calculation results at rated speed of 150rpm

\begin{tabular}{l|cc}
\hline Losses/ model & Iron losses $(W)$ & Joule losses $(W)$ \\
\hline FE-Conv. & 220 & 40 \\
Exp.-Conv. & 219 & 44 \\
FE-2-ducts & 198 & 43 \\
Exp.-2-ducts & 201 & 42 \\
FE-4-ducts & 171 & 44 \\
Exp.-4-ducts & 170 & 43 \\
\hline
\end{tabular}

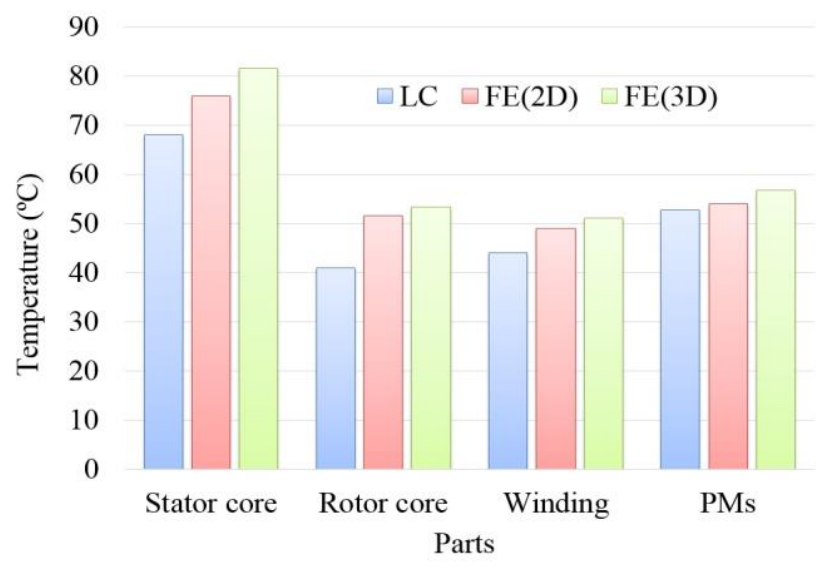

Fig. 4 Comparison of steady-state temperature distribution in the machine's parts of the initial model using LC and FE methods

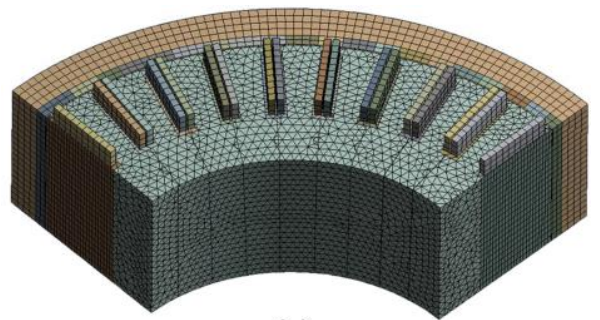

(a)

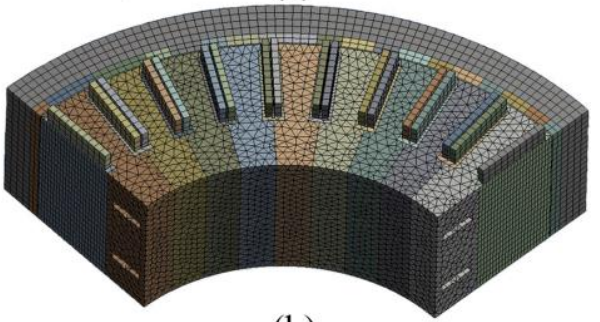

(b)

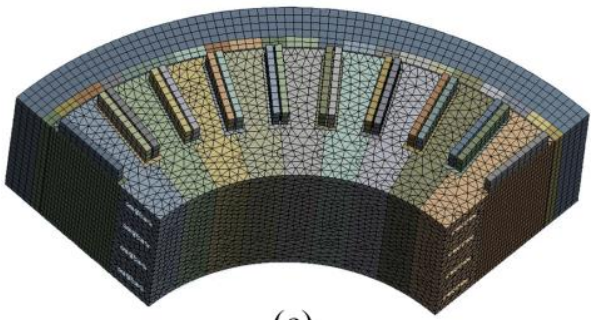

(c)

Fig. 5 3-D generated mesh for a) conventional, b) 2-ducts, and c) 4-ducts FE models

\section{Results and discussion}

The mesh generation is successfully generated (Fig. 5) for the conventional, two-ducts, and 4-ducts models with 367691 nodes and 146213 elements, 382517 nodes and 153400 elements, and 389945 nodes and 158988 elements, respectively.

This section is classified into two parts, one the results of the transient thermal analysis using 3-D FEA for all introduced FE models, and next it will be a general comparison and discussion on the other aspects. Thereupon, a thermal modelling of the conventional, 2-ducts, and 4ducts FE models using lumpedcircuit can be addressed in Fig. 6. A steady-state temperature distribution and improvement trend throughout the models is shown, where convection, power sources, delta temperatures (trapezius blocks), and thermal resistance blocks are presented. It should be noted that the blocks with temperature and power tags are for steady-state temperature (or power) of conventional, 2- 


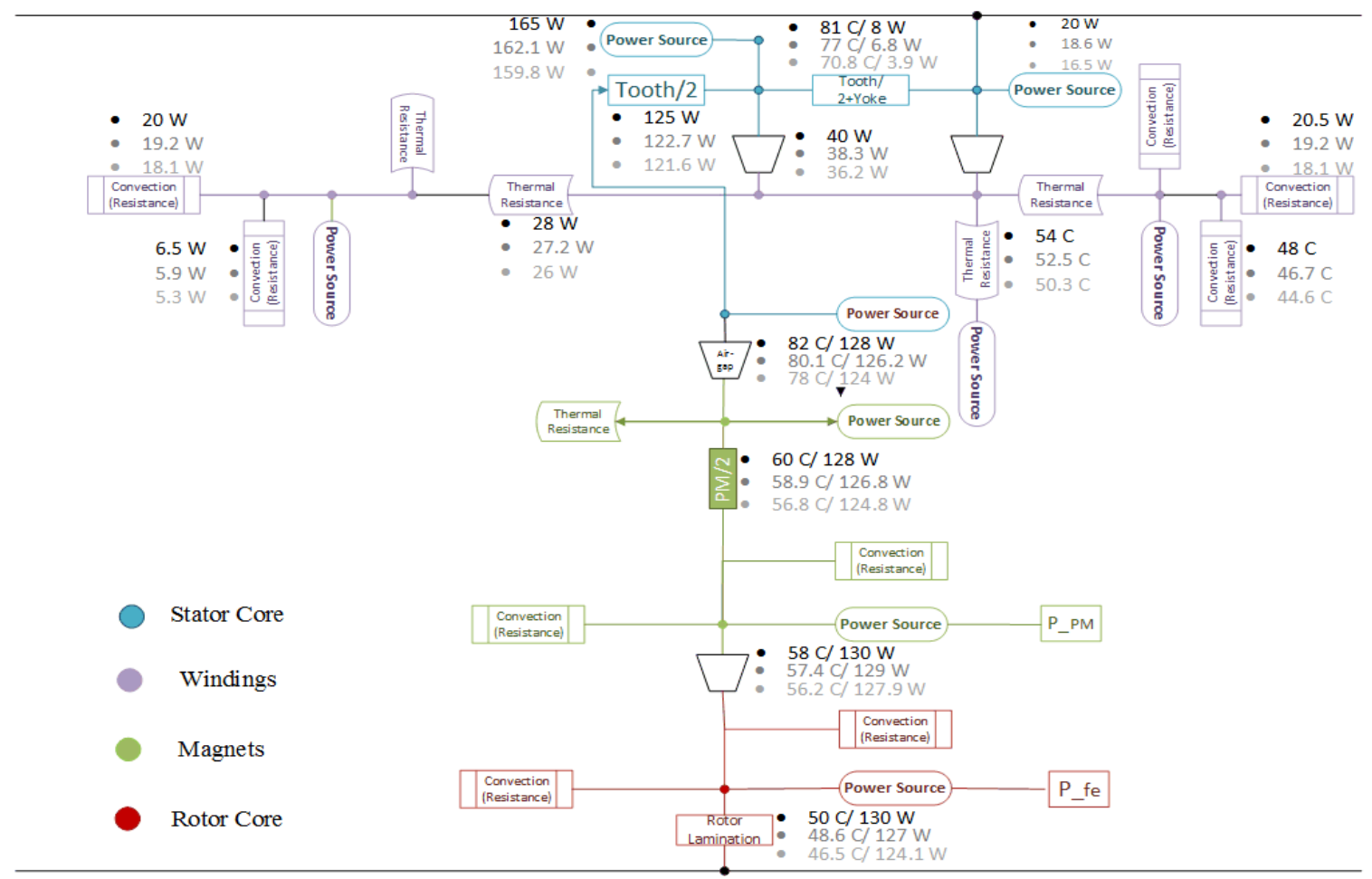

Fig. 6 Lumped-circuit modeling of the FE models ducts, and 4-ducts models, respectively. For example, in thermal resistance block of stator core that named by “Tooth/2+Yoke", $81\left({ }^{\circ} \mathrm{C}\right) / 8(\mathrm{~W})$ is reported for initial model, and $73.8\left({ }^{\circ} \mathrm{C}\right) / 3.9(\mathrm{~W})$ stands for 4 -ducts model

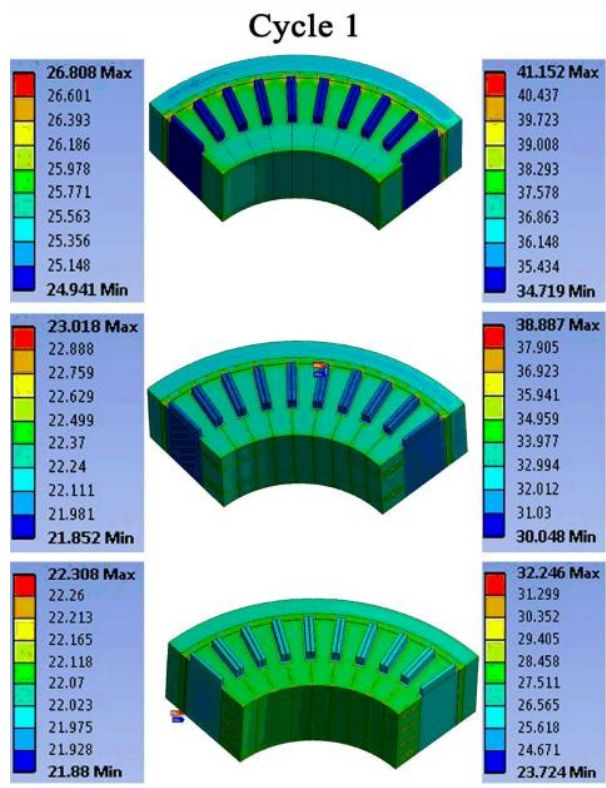

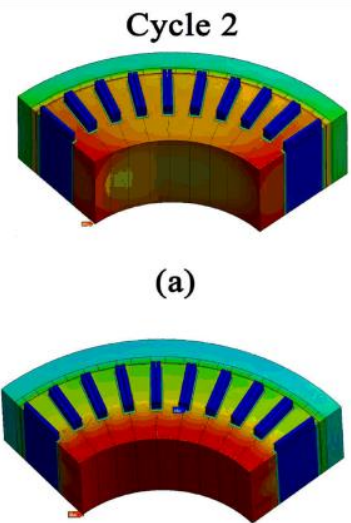

(b)

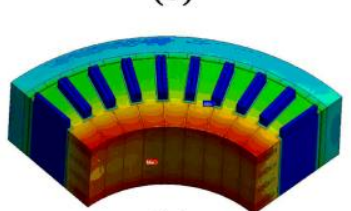

(c)
Cycle 3
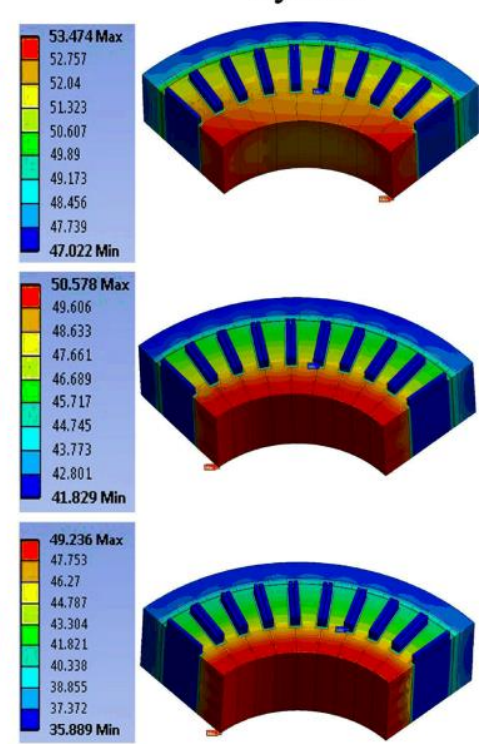

Fig. 7 3D transient thermal FEA by 3 cycles, a) conventional model, b) 2-ducts model, and c) 4-ducts model at 1st, 2nd , and 3rd

The aim of natural air cooling is removing the heat in the stator core through the innovative models, in which electromagnetic performance of the generator is included as a constraint of the technique's improvement. Fig. 4(a) presents the temperature-rise performance of the innovative models. This figure illustrates the results enclosed by less than 3\% from 2-D FEA in compare to 3-D FEA, also a very good prediction among the models can be seen in where the temperature difference between the conventional model and 4-ducts model is approximately for $11.0\left({ }^{\circ} \mathrm{C}\right)$. In addition to, the influence of ductwidth on other design highlights as back-EMF, and electromagnetic torque are described via Fig. 8(b). The graph illustrated that through increasing the volume of the ducts, the back-EMF and EM torque decreases strongly. The back-EMF and EM torque for two-ducts, and four- ducts models are 305 (v), 350 (N.m), and 260 (v), 338 (N.m), respectively.

In Fig. 7(a), the temperature distribution of the first-cycle is shown, in which the conventional model varies between 24.941 up to $26.808\left({ }^{\circ} \mathrm{C}\right)$. Although, the two-ducts FE model with segmented stator core (model Fig.7-b) resulted in a better temperature distribution performance that varies between 21.852 up to $23.018\left({ }^{\circ} \mathrm{C}\right)$. At last, the best achieved performance is 
clearly seen through four-ducts innovative model with segmented stator core, shown as model (c) with temperature distribution performance from 21.88 up to $22.308\left({ }^{\circ} \mathrm{C}\right)$. Additionally, in this cycle all the models are pointed the same parts by minimum and maximum probes in blue and red labels, respectively.

In the second cycle, models (Fig. 7(a), (b), and (c) are shown a temperature-rise in comparison with the corresponding models in the first-cycle of analysis. The conventional model (Fig.7-a) is illustrated temperature distribution variation of 34.7 to 41.15 $\left({ }^{\circ} \mathrm{C}\right)$. The two-ducts model (Fig.7-b) resulted in a maximum temperature distribution at the stator yoke. In this model, the temperature varies from 30 to $38.8\left({ }^{\circ} \mathrm{C}\right)$. The four-ducts model (Fig. 7-c) with a better thermal performance, in which the temperature varies between 23.724 up to $32.246\left({ }^{\circ} \mathrm{C}\right)$, and the same parts for maximum and minimum temperature labels with other models in this cycle.

In the third-cycle, all models are carried out the maximum temperature label at the stator core due to segmentation. The conventional model (Fig.7-a) is illustrated the peak temperature in comparison to the two-ducts model (Fig.7-b) varies from 47.822 up to $53.474\left({ }^{\circ} \mathrm{C}\right)$, and the four-ducts model (Fig.6-c) with a better performance varies between 41.829 to $50.578\left({ }^{\circ} \mathrm{C}\right)$. At last, the four-ducts model has presented the best cooling performance to remove the heat.

In Fig. 8, the influence of the duct-width on the electromagnetic key parameters such as back-EMF and torque is shown in Fig. 8-a. Also, the temperature-rise and power can be seen in Fig. 8-b, in which the duct width $r=3.8$ ( $\mathrm{mm}$ ) was chosen for the innovative models.

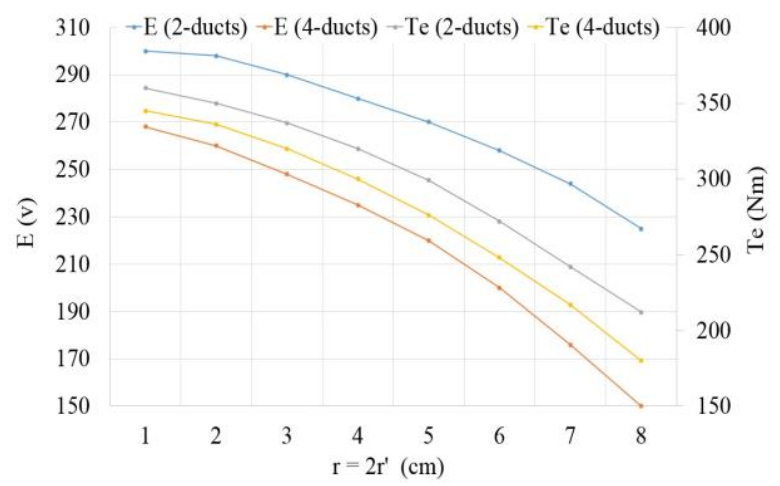

(a)

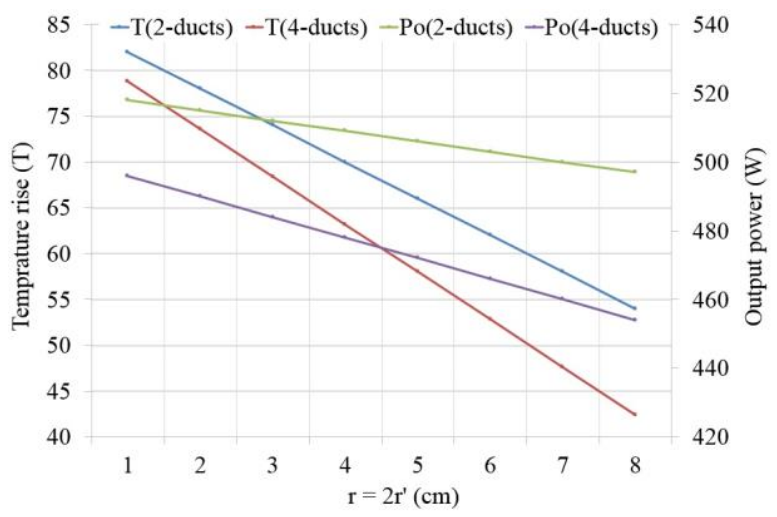

(b)

Fig. 8 Influence of duct-width on a) the back-EMF and torque, as well as b) temperature-rise and output power

\section{Experimental investigation}

Essentially, the heat transfer is known as one the most critical parameters in the thermal design of the PMSMs, thus, the most sensitive heat transfer coefficients are calculated and also experimentally reported in Fig 9 under following conditions

- The axial inlet velocity of the cooling air was defined between 0.5 to $3(\mathrm{~m} / \mathrm{s})$

- The rotor tip velocity is varied between 2 to $8(\mathrm{~m} / \mathrm{s})$

- The air approach angle is defined between 0 to $30^{\circ}$

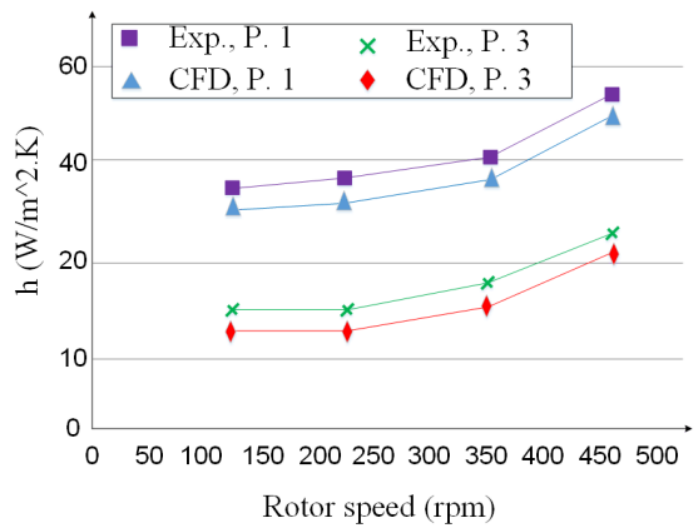

(a)

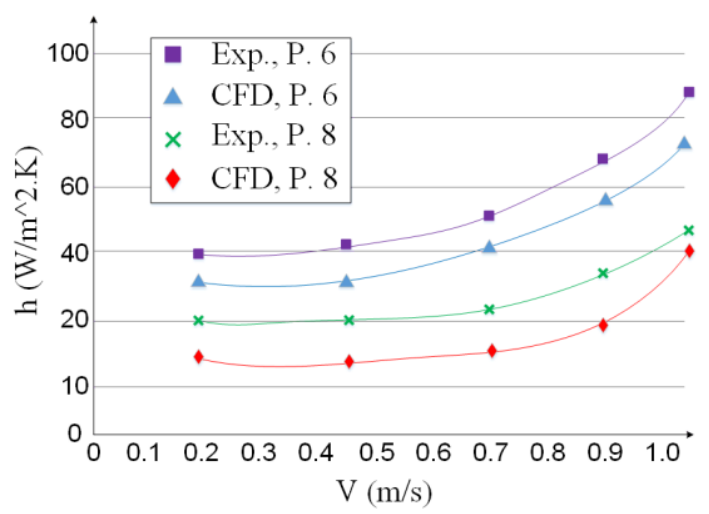

(b)

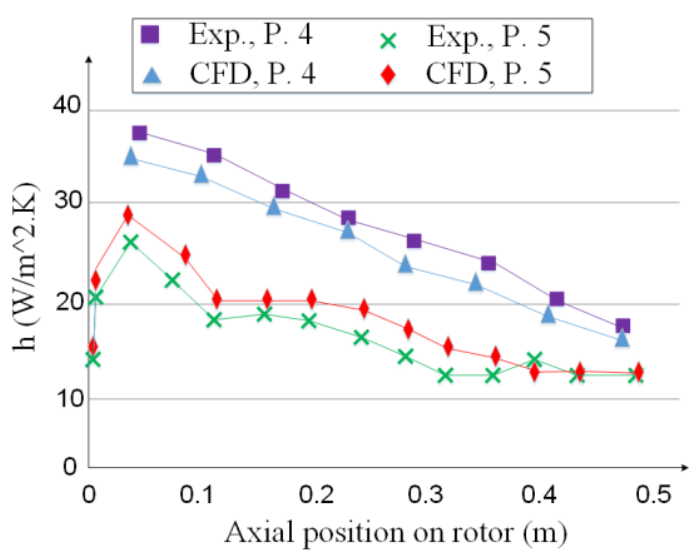

(c)

Fig. 9 Heat transfer coefficients verification for the FE models, a) at points 1 and 3 variable airflow rate, b) at points 6 and 8 for variable rotor speed, and c) at points 4 and 5 for variable rotor speed

it should be mentioned that not significant different is seen for the change of the air approach angle from 0 to $60^{\circ}$. Fig. 9(a) 
illustrates the change of heat transfer coefficients at the poles (points 1 and 3) at a variable speed condition. In Fig. 9(b), the heat transfer coefficients are at the stator core (points 6 and 8), in which the low velocity ratio (axial inlet velocity/ rotor tip velocity) is variable. Fig. 9(c), presents the surface heat transfer coefficients around the bottom face of the field coil at the leading side of magnet (points 4), and bottom face of the field coil at trailing side of pole (point 5).

The optimized SPMSG under test is fed through a variable speed frequency converter known as ABB ACS600 and loaded by a DC machine. The electrical output power is measured by a power analyzer known as Yokogawa PZ4000 by accuracy of 1\%, and the temperature is registered in twenty points by Pt-100 temperature sensors. The manufactured prototype is employed for the small power generation using wind energy along the coast of Barcelona city in Spain.

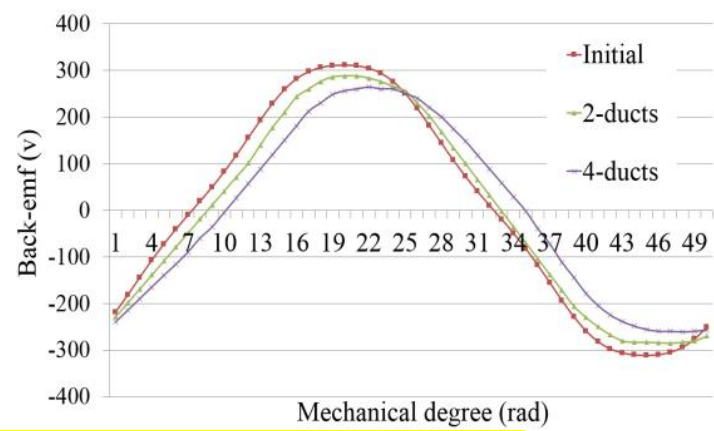

Fig. 10 Back-EMF trend for the FE models

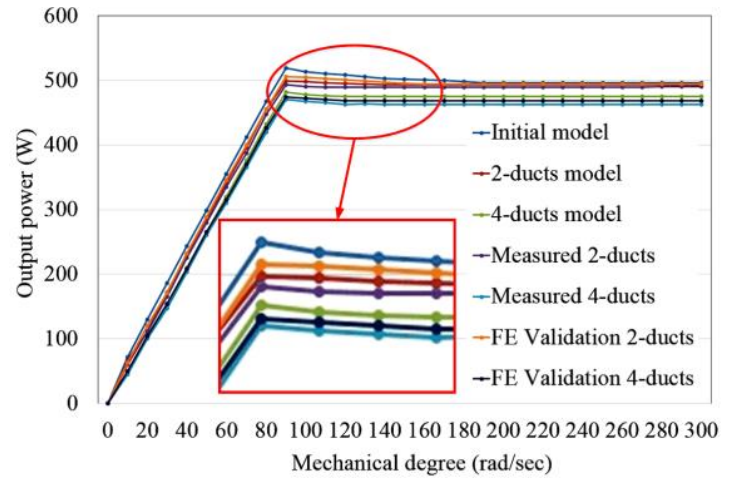

Fig. 11 Predicted output power in comparison with experimental

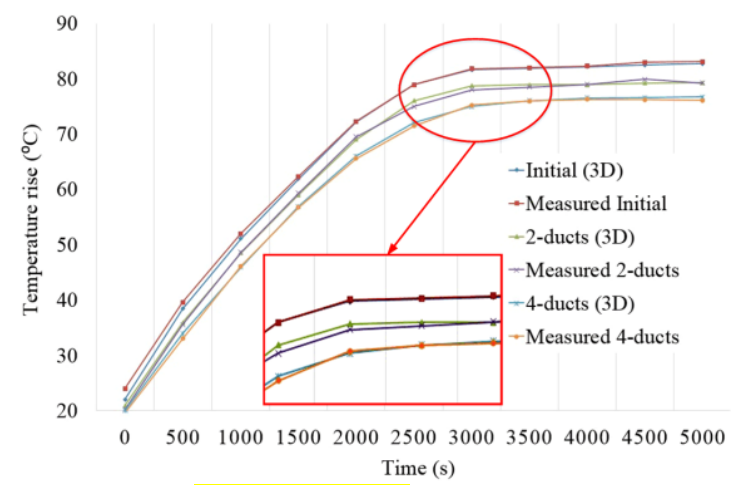

Fig. 12 Predicted temperature-rise in comparison with experimental

The main objective is the temperature-rise, in addition, the performance aspects have to be reliable such as the measured output power in comparison with the conventional, and the innovative FE-models which can be seen in Fig. 11, where temperature-rise improvement can be seen in Fig. 12. A considerable accuracy between FE models and measured values presents a great fitness of the shape optimization design. The manufactured PMSG can be seen in Fig. 13(a) through segmented stator core for improving slot fill factor, simpler winding, and providing closed-slot topology. In Fig. 13(b), the rotor included the skewed magnets. Additionally, the prototype is used for the wind energy application, the installed vertical axis twisted savonius type wind turbine (VAWT) at the top of PMSG as shown in Fig. 13-c.

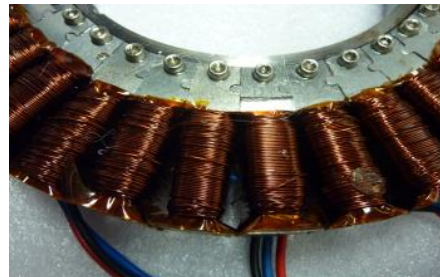

(a)

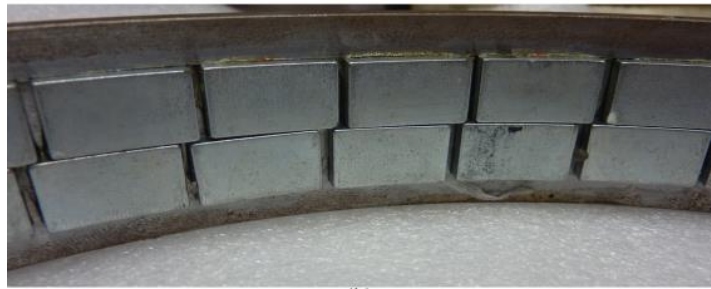

(b)
Fig. 13 Manufactured 4-ducts model, a) The PMSG with segmented stator core, b) The rotor core with skewed PMs, and c) The assembled SPMSG and the VAWT at the top of PMSG

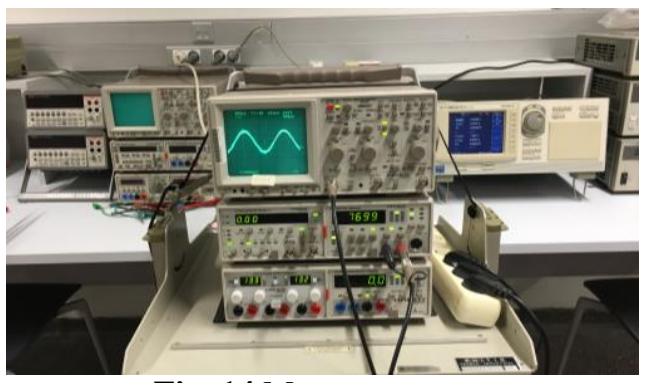

Fig. 14 Measurement setup

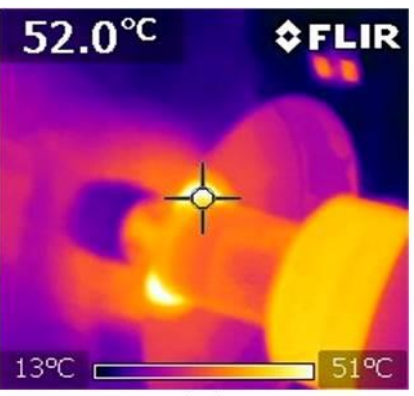

(a)

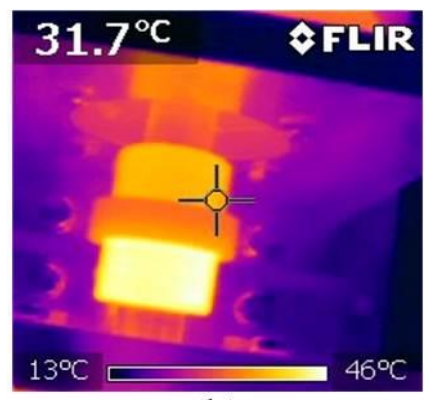

(b)
Fig. 15 Use of thermal imaging measurement on the test bench at rated speed of $150(\mathrm{rpm})$, a) the inner surface of stator core, and b) the housing

A good electromagnetic performance is reported for the innovative models. Although, a trade-off can be thinkable due to output power changing among the models. One the other hand, the measurement setup for iron losses calculation is presented in Fig. 14, and correspondingly the results are reported in the Table. 3 , where there is a considerable iron losses reduction via innovative models as the shape optimization is done in the stator yoke. 
Fig. 15 illustrates that the set of boundary and related thermal 3-D analysis is successfully performed, in which the proposed four-ducts innovative FE model (in Fig. 7-c) is recorded 49.23 $\left({ }^{\circ} \mathrm{C}\right)$ and experimentally verified by $52.0\left({ }^{\circ} \mathrm{C}\right)$. Of course, a very small error always exist between numerical and experimental calculations

The coolant solution of the proposed model (in terms of manufacturing process), where the stator core is divided into a number of substacks which can be seen in Fig. 13-a. Cooling air flows into axial ducts due to rotation of the shaft and its way to out of housing. Thus, the stator via circumferential cooling channels formed between the adjacent stator substacks. The use of the stator substacks has an effect on the equivalent length of the generator, and therefore, if ignored, leads to an incorrect noload voltage and synchronous inductance calculation.

\section{Conclusion}

The problem of high temperature-rise is investigated due to the segmentation in the stator core with $81\left({ }^{\circ} \mathrm{C}\right)$ at $150(\mathrm{rpm})$ which becomes the main objective for further post-action design study. Thus, the achievement is to decrease the temperature-rise at the stator core using an innovative coolant.

In this paper, an innovative cooling system with natural airflow technique in order to reduce temperature-rise at the stator core is presented through two innovative FE models with circumferential and axial ducts. The main objective under following constraints have been successfully achieved, in which the efficiency of $\eta_{i} \geq \% 96$, and $P_{0 i} \geq 465(\mathrm{~W})$ are defined. Consequently, the innovative 2-ducts and 4-ducts FE models are studied, where a significant temperature reduction up to $11\left({ }^{\circ} \mathrm{C}\right)$ with freezing the electromagnetic capability is reported by the proposed four-ducts model. Also, its heat transfer path is emphasized. Additionally, the outcome of the cooling system is highlighted under the influence of the duct-width on the key EM parameters such as the back-EMF, torque, output power, and also temperature-rise (constraints). The achievements of the study is perfectly reached, in which the results of all 3-D FEA models have obviously compared through the constraints and experimentally. At last, measured experimental results greatly support the design technique by a very small error of $\varepsilon<2.5 \%$.

\section{References and notes}

1. W. Chu, Z. Zhu, and Y. Shen,: 'Analytical optimisation of external rotor permanent magnet machines', IET Electrical Systems in Transportation, doi: 10.1049/iet-est.2012.0045, pp.41-49, 2013.

2. R. Wrobel, P. H. Mellor, and D. Holliday,: 'Thermal Modeling of a Segmented Stator Winding Design', IEEE Trans. on INDUSTRY APPLICATIONS, VOL. 47, NO. 5, pp.2023-2025, 2011

3. H. Li, and Y. Shen,: 'Thermal Analysis of the Permanent-Magnet Spherical Motor', IEEE Trans. on ENERGY CONVERSION, Vol. 30, No. 3 pp. 1-2, 2015.

4. M. Polikarpova, P. Ponomarev, P. Röyttä, and et al.: 'Direct liquid cooling for an outer-rotor direct drive permanent-magnet synchronous generator for wind farm applications', Journal of IET Electric Power Applications, ISSN. 1751-8660, pp. 523-526, doi: 10.1049/iet-epa.2014.0342, 2015.

5. Xikai Sun, and Ming Cheng,: 'Thermal Analysis and Cooling System Design of Dual Mechanical Port Machine for Wind Power Application', IEEE Trans. on Industrial Elec., Vol. 60, no. 5, doi: 10.1109/TIE.2012.2190958, pp.1724-1732, 2013.

6. G. Lei, and et al.: 'Techniques for Multilevel Design Optimization of Permanent Magnet Motors', IEEE TRANSACTIONS ON ENERGY CONVERSION, VOL. 30, NO. 4, DECEMBER 2015, pp. 1574-1582, DOI: 10.1109/TEC.2015.2444434, 2015

7. Pedram Asef, R. B. Perpina, and M. R. Barzegaran,: 'Robust Design for Power Maximization Using Dual-Level Response Surface Methodology and Booth's Algorithm', IEEE Trans. on Energy Conversion, ID: TEC- 00229-2017, 2016.
8. M. Tursini., and et al., "A switched-reluctance motor for aerospace application: Design, analysis and results." Electric Power Systems Research 142 (2017): 74-83.

9. Adrian Pleşca. "Thermal analysis of a traction system with double conducting points in steady state conditions." Electric Power Systems Research 97 (2013): 126-132.

10. Staudt, Tiago, et al. "An optimization-oriented sizing model for brushless doubly fed reluctance machines: Development and experimental validation." Electric Power Systems Research 132 (2016): 125-131

11. D. A. Staton, A. Boglietti, and A. Cavagnino,: 'Solving the more difficult aspects of electric motor thermal analysis in small and medium size industrial induction motors', IEEE Trans. Energy Convers., vol. 20, no. 3, pp. 620-628, Sep. 2005

12. D. A. Staton and A. Cavagnino,: 'Convection heat transfer and flow calculations suitable for electric machines thermal models', IEEE Trans. Ind. Electron., vol. 55, no. 10, pp. 3509-3516.

13. A. Boglietti, A. Cavagnino, and D. Staton,: 'Determination of critical parameters in electrical machine thermal models', IEEE Trans. Ind. Appl., vol. 44, no. 4, pp. 1150-1159, Jul./Aug. 2008.

14. A. Boglietti, A. Cavagnino, D. Staton, and et al.: 'Evolution and modern approaches for thermal analysis of electrical machines', IEEE Trans. Ind. Electron., vol. 56, no. 3, pp. 871-882, 2009.

15. Gómez, D. J., et al. 'Experimental validation of an enhanced permeance network model for embedded magnet synchronous machines. ' Electric Power Systems Research 140,2016: 836-845.

16. G. J. Li, J. Ojeda, E. Hoang, and et al.: 'Comparative studies between classical and mutually coupled switched reluctance motors using thermal-electromagnetic analysis for driving cycles', IEEE Trans. Magn., vol. 47, no. 4, pp. 839-847, Apr. 2011.

17. Yusuf Yasa, Sincar, E., Ertugrul, B. T., \& Mese, E. "A multidisciplinary design approach for electromagnetic brakes." Electric Power Systems Research 141 (2016): 165-178.

18. A. Tenconi, F. Profumo, S. E. Bauer, and .: 'Temperatures evaluation in an integrated motor drive for traction applications', IEEE Trans. Ind. Electron., vol. 55, no. 10, pp. 3619-3626.

19. Y. Huang, J. Zhu, and Y. Guo,: 'Thermal analysis of high-speed SMC motor based on thermal network and 3-D FEA with rotational core loss included' IEEE Trans. Magn., vol. 45, no. 10, pp. 4680-4683, Oct. 2009.

20. T. A. Jankowski, F. C. Prenger, D. D. Hill, and et al.: 'Development and validation of a thermal model for electric induction motors," IEEE Trans.Ind. Electron., vol. 57, no. 12, pp. 4043-4054, Dec. 2010

21. Marco Tosetti, and et al.: 'Conjugate Heat Transfer Analysis of Integrated Brushless Generators for More Electric Engines', IEEE Trans. Industry Applications, Vol. 50, No. 4, pp. 2467-2474, July.

22. N. S. Ottosen, and H. Petersson, "Introduction to the Finite Element Method," ISBN-13: 978-0134738772, Chapter. 20.3, Prentice Hall, October 1992.

23. N. Zhao, Z. Q. Zhu, W. Liu, "Thermal Analysis and Comparison of Permanent Magnet Motor and Generator," IEEE International Conference on Electrical Machines and Systems (ICEMS), DOI: 10.1109/ICEMS.2011.6073482, pp, pp.1-3, 2011

24. Y. K. Chin, and D. A. Staton "Transient thermal analysis using both lumped-circuit approach and finite element method of a permanent magnet traction motor," IEEE 7th AFRICON Conference in Africa, 1027- 1035 Vol.2, doi: 10.1109/AFRICON.2004.1406847, 2004.

25. A. M. Knight, Y. Zhan, D. A. Staton, and et al.: 'Influence of stator slot shape on temperature in surface mounted permanent magnet machines', in Proc. IEEE-ECCE, Sep. 2010, pp. 17531759 .

26. D. G. Dorrell, A. M. Knight, M. Popescu, and et al. 'Comparison of different motor design drives for hybrid electric vehicles', in Proc. IEEE ECCE, Sep. 2010, pp. 3352-3359.

27. C. Mejuto, M. Mueller, M. Shanel, and et al.: 'Improved synchronous machine thermal modelling', in Proc. XVIII ICEM, Sep. 6-9, pp. 1-6, 2008.

28. A. Boglietti, A. Cavagnino, D. A. Staton, and et al.: 'End space heat transfer coefficient determination for different induction motor enclosure types', in Conf. Rec. 43rd IEEE IAS Annu. Meeting, Oct. 2008, pp. 1-8.

29. P. Asef, R. B. Perpina, M. R. Barzegaran, J. Dong, A. Lapthorn, and O. A. Mohammed.: 'An advanced quasi-FEA technique on iron losses prediction for permanent magnet synchronous machines', IEEE Trans on Mgn., id: TMAG-17-06-0445, pp. 1-8.

30. D. M. Ionel, M. Popescu, M. I. McGilp, T. J. E. Miller, S. J. Dellinger, and R. J. Heideman, "Computation of Core Losses in 
Electrical Machines Using Improved Models for Laminated

Steel," IEEE Trans. Ind. Appl., vol. 43, no. 6, pp. $1554-1564$,

2007. 